\title{
Biochemical and genetic studies on the function of, and relationship between, the PGII- and CDC30-encoded phosphoglucose isomerases in Saccharomyces cerevisiae
}

\author{
J. RICHARD DICKINSON
}

School of Pure and Applied Biology, University of Wales College of Cardiff, PO Box 915, Cardiff CFI 3TL, UK

(Received 11 July 1990; revised 21 November 1990; accepted 21 December 1990)

\begin{abstract}
Isoelectric focusing was used to compare the complement of phosphoglucose isomerase isoenzymes in a wild-type strain of Saccharomyces cerevisiae and in a strain with a deletion in the PGII structural gene. Deletion of the PGII gene did not result in the absence of the high- $K_{\mathrm{m}}$ isoenzyme I but the low- $K_{\mathrm{m}}$ isoenzyme II was absent. Hence, the isoenzymes must be the products of two genes. If $P G I I$ were the sole structural gene its deletion would result in the disappearance of both isoenzymes. After a temperature shift-up a cdc30-bearing strain had cell cycle arrested and contained only $8 \%$ of the polysaccharide in the wild-type. Phosphoglucose isomerase is required for the synthesis of fructose 6-phosphate (F6-P), a precursor of the cell wall components chitin and mannoprotein ('mannan'), which are a polysaccharide and contain polysaccharide, respectively. Since the $c d c 30$ mutation confers a temperaturesensitive phosphoglucose isomerase, the likely explanation for cell cycle arrest caused by this mutation is that the defective phosphoglucose isomerase results in a reduction of F6-P and hence an inability to synthesize the mannan and chitin needed for cytokinesis and cell separation. Revertants of a pgil-1 bearing strain were selected for their ability to grow on glucose at $25^{\circ} \mathrm{C}$ and this yielded a number of different phenotypes. Amongst the isolates was a strain which had undergone an intragenic reversion at the pgil locus, designated pgil-1,100. This mutation permits growth and cell division at $25{ }^{\circ} \mathrm{C}$ but results in cell cycle arrest at $36^{\circ} \mathrm{C}$. These results are all consistent with the notion that in $S$. cerevisiae there are two genes ( $P G I I$ and $C D C 30)$ which encode the low- $K_{m}$ and high- $K_{m}$ isoenzymes, respectively, of phosphoglucose isomerase and that the two gene products physically interact for activity.
\end{abstract}

\section{Introduction}

Phosphoglucose isomerase catalyses the interconversion of glucose 6-phosphate (G6-P) and fructose 6-phosphate (F6-P) and hence forms an integral part of both glycolysis and gluconeogenesis. Previous work in my laboratory has revealed that in Saccharomyces cerevisiae there are two genes, $P G I 1$ and $C D C 30$, encoding low- $K_{\mathrm{m}}$ and high$K_{\mathrm{m}}$ isoenzymes, respectively, of phosphoglucose isomerase (Dickinson \& Williams, 1987; Dickinson et al., 1988). There is dissent from this view on genetic grounds because other workers have shown that mutation in, or deletion of the single gene $P G I 1$ results in loss of enzyme activity and an inability to grow on glucose (Clifton et al., 1978; Herrera \& Pascual, 1978; Ciriacy \& Breitenbach, 1979; Maitra, 1971; Maitra \& Lobo, 1977; Aguilera,

Abbreviations: G6-P, glucose 6-phosphate; F6-P, fructose 6phosphate.
1986). Hence the simplest conclusion, that only the $P G I I$ gene is required. However, the long-standing biochemical evidence from Noltmann's group (Nakagawa \& Noltmann, 1967; Kempe et al., 1974a,b) of isoenzymes of phosphoglucose isomerase still needs adequate explanation. There have been various attempts to dismiss the work, including the observation that the strain of yeast used by Noltmann and co-workers was not well described: this hardly constitutes a denial of the results obtained. There has also been the suggestion made that this group took insufficient care to prevent (for example) proteolytic degradation of a single enzyme prior to electrophoretic analysis, which is a direct contradiction of the literature. Southern analysis has revealed only one copy of the $P G I I$ gene per haploid genome in $S$. cerevisiae (Aguilera \& Zimmermann, 1986; Green et al., 1988). This particular result is sometimes wrongly stated as having demonstrated that there is only one gene coding for phosphoglucose isomerase. All it shows is that there are 
no other genes in the yeast genome with significant nucleotide homology to the $P G I I$ gene. There are several other explanations, including the possibility that different codons are deliberately used to specify a similar amino acid sequence or that the two isoenzymes represent a case of convergent evolution, where one would not be surprised to find different nucleotide sequences. All of this can be reconciled by the slightly more complicated view in which the PGII and $C D C 30$ gene products (the two isoenzymes) physically interact for activity. Thus inactivation of either isoenzyme by mutation in the requisite gene would be expected to result in a loss of enzyme activity. In this study, in an attempt to clarify the relationship between the $P G I I$ - and $C D C 30$-encoded isoenzymes, isoelectric focusing was used to compare the isoenzyme complement in a wildtype strain and in a strain with a deletion in the PGII structural gene.

It is not immediately obvious why temperaturesensitive mutations in genes such as $P Y K I$ (Kawasaki, 1979), PGII and CDC30 (PGI2) which encode enzymes of intermediary metabolism should be cell cycle mutations, though one possible reason is that these enzyme activities are required at specific times during the cell cycle. When a yeast cell is growing on glucose, phosphoglucose isomerase converts G6-P to F6-P. Besides being an essential intermediate of the glycolytic pathway, F6-P is the precursor for the synthesis of the key cell wall constituents mannoprotein ('mannan') and chitin. In an attempt to explain the phenotype of $c d c 30$ bearing mutants in relation to phosphoglucose isomerase activity the polysaccharide content of wild-type and $c d c 30$-arrested cells was determined.

The question as to why particular mutations should cause arrest of $S$. cerevisiae with a uniform terminal phenotype (i.e. why these should be cell cycle mutations) has been considered in a wide context. This has been done by addressing questions such as 'Does the use of different mutagenic agents and/or different protocols for the selection of mutants result in the identification of novel phenotypes or hitherto undiscovered genes?' It appears that such investigations have generally resulted only in the isolation of further alleles of genes that were previously known (Kaback et al., 1984; Pringle, 1987). This line of enquiry is particularly intriguing in the case of phosphoglucose isomerase, where there are two genes encoding distinct isoenzymes with different kinetic properties (Dickinson \& Williams, 1987; Dickinson et al., 1988). Mutations in the PGII gene that have been described previously are absolute mutations rendering yeast unable to grow on glucose-containing media (Maitra, 1971 ; Maitra \& Lobo, 1977; Clifton et al., 1978; Herrera \& Pascual, 1978; Ciriacy \& Breitenbach, 1979). These result in arrest at all stages of the cell cycle when cells are transferred from a gluconeogenic carbon source to glucose. Mutations in the $C D C 30$ gene result in temperature-sensitive cell cycle arrest on glucose (Kawasaki, 1979; Dickinson \& Williams, 1987). The rationale for part of the present work was that if the PGII and CDC30 gene products interact, then it ought to be possible to isolate a mutant affected in the PGII-encoded protein such that the altered interaction between isoenzymes results in cell cycle stage-specific arrest.

\section{Methods}

Strains, media and genetical procedures. Strain A364A (MATa adel ade 2 ural his7 lys 2 tyrl gall), which was used as the standard wild-type, and strain 23015 (MATa adel ade 2 ural his 7 lys 2 tyr 1 gall cdc30-I) were both from the Yeast Genetic Stock Center (Berkeley, California, USA). Strain JPT99 (MATa $c d c 30-3$ ) was from J. Pringle (University of Michigan, Ann Arbor, Michigan, USA). Strain AAG2 (MATa ura3 canl pgil $\triangle 25:: L E U 2$ ), which has a deletion of about $80 \%$ of the $P G I 1$ gene and replacement with the LEU2 gene (Aguilera, 1986), was supplied by A. Aguilera (NYU Medical Center, New York, New York, USA). The prototrophic haploid 395 (MAT $\alpha$ pgil-I), obtained originally from P. Maitra (Tata Institute of Fundamental Research, Bombay, India), was the strain from which all revertants were isolated. Strain 59.4A (MATa/MAT 2 HO/HO arg4-1/arg4-1 cyhl/cyhl spd1-1/ spd $1-1$ ), homozygous for the spdI mutation, which was used in the analysis of revertants, has been described (Dickinson \& Dawes, 1983).

Complex media contained, per litre: yeast extract $(10 \mathrm{~g})$, bacteriological peptone $(20 \mathrm{~g})$, adenine $(0 \cdot 1 \mathrm{~g})$, uracil $(0 \cdot 1 \mathrm{~g})$ and the specified carbon source (YEPD $20 \mathrm{~g}$ D-glucose, YEPE $10 \mathrm{ml}$ ethanol; YEPF $20 \mathrm{~g}$ D-fructose; YEPG $30 \mathrm{ml}$ glycerol). Growth of the pgil $\triangle$ strain AAG2 required that the YEPF medium was supplemented with $0.055 \%$ glucose (Aguilera, 1986). The minimal medium comprised, per litre: glucose $(20 \mathrm{~g})$, Bacto Yeast Nitrogen Base without amino acids and ammonium sulphate $(1.67 \mathrm{~g})$, ammonium sulphate $(5 \mathrm{~g})$ and auxotrophic supplements as required at $100 \mathrm{mg} \mathrm{l}^{-1}$. All solid media contained agar $\left(20 \mathrm{~g} \mathrm{l}^{-1}\right)$.

Standard genetic techniques were used for mating, sporulation and dissection (Sherman, 1975; Mortimer \& Hawthorne, 1975). Crosses involving the homothallic diploid 59.4A were performed using cultures which had been sporulated prior to mating.

Isoelectric focusing and polysaccharide determinations. Isoelectric focusing was done largely as described previously (Dickinson et al., 1988) except instead of using ultra-thin $0.3 \mathrm{~mm}$ gels, $1 \mathrm{~mm}$ gels were prepared and cast according to the manufacturer's (Pharmacia) instructions. Prefocusing was at $30 \mathrm{~W}$ for $40 \mathrm{~min}$. The cell extracts were applied directly to the gel then focusing was for $80 \mathrm{~min}$ at $30 \mathrm{~W}$ constant power.

For total cellular polysaccharide determinations cells were harvested by filtration using cellulose acetate membrane filters $(0.45 \mu \mathrm{m}$ grade), and washed with distilled water. The cells were then resuspended in distilled water and total polysaccharide was determined by the method of Dubois et al. (1956). D-Glucose was used as standard and all determinations were expressed as 'glucose equivalents'.

Isolation of revertants of pgil-1 mutants. Cells of strain 395 were plated-out onto YEPD medium and incubated at $25^{\circ} \mathrm{C}$. This strain, by virtue of carrying the glycolytic lesion pgil, does not grow on glucosecontaining media. Papillae which arose after about $5 \mathrm{~d}$ incubation were transferred to fresh YEPD plates, reincubated at $25^{\circ} \mathrm{C}$ and then replica-plated to YEPD, YEPE and YEPG media at $25^{\circ} \mathrm{C}$ and $36{ }^{\circ} \mathrm{C}$ to test for temperature-sensitivity on the different carbon sources. 
Temperature shift-up of strains in liquid media. The initial screening merely revealed which revertants were temperature-sensitive on different media. In order to ascertain if any of the strains that were temperature-sensitive on YEPD were cell cycle mutants $5 \mathrm{ml}$ cultures were grown in test tubes with shaking at $25^{\circ} \mathrm{C}$. The cultures were then shifted to $36^{\circ} \mathrm{C}$ for $5 \mathrm{~h}$, after which they were examined microscopically. When determining the percentage of cells that were budded, at least 400 cells were scored. Those which showed a uniform terminal phenotype were subjected to further detailed examination. Cell number was determined using a Coulter counter.

\section{Results and Discussion}

Deletion of the PGII gene results in loss of isoenzyme II but not isoenzyme I of phosphoglucose isomerase

Fig. 1 shows an isoelectric focusing gel in which the isoenzymes of phosphoglucose isomerase have been separated. The wild-type strain A364A contains both isoenzymes whereas strain AAG2 with the deletion in the $P G I I$ gene lacks isoenzyme II (the low- $K_{\mathrm{m}}$ isoenzyme) and contains only the $C D C 30$-encoded (high- $K_{\mathrm{m}}$ ) isoenzyme I. This is evidence that the isoenzymes of phosphoglucose isomerase are genuine products of different genes. If $P G I I$ were the sole structural gene its deletion would result in the disappearance of both isoenzymes.

More bands can be seen in this gel than in the isoelectric focusing gel reported previously (Dickinson $e t$ al., 1988). The current work necessitated the use of a fructose-containing medium to permit the growth of the pgils strain AAG2. Naturally, the wild-type was cultured in the same medium. In the previous study glucose was used as carbon source. The cells contain less of both isoenzymes of phosphoglucose isomerase when grown in YEPF compared with growth in YEPD, hence the need to load much greater amounts of protein onto the $1 \mathrm{~mm}$ thickness gel used here compared with the ultra-thin $(0.3 \mathrm{~mm})$ gels used in the earlier work. Consequently one can see additional less abundant proteins that were not detected previously. The net result of all this is that the present gels appear less 'clean' than those published earlier. The identity of the band immediately 'above' the $C D C 30$ gene product that is present in A364A but not in AAG2 is unknown.

The cdc30 mutation which causes a defect in phosphoglucose isomerase also results in reduced polysaccharide content

During growth on glucose, phosphoglucose isomerase converts G6-P to F6-P. In addition to being an intermediate in glycolysis, F6-P is the biosynthetic precursor of the cell wall components mannan and chitin. It is known that cell separation is accompanied by

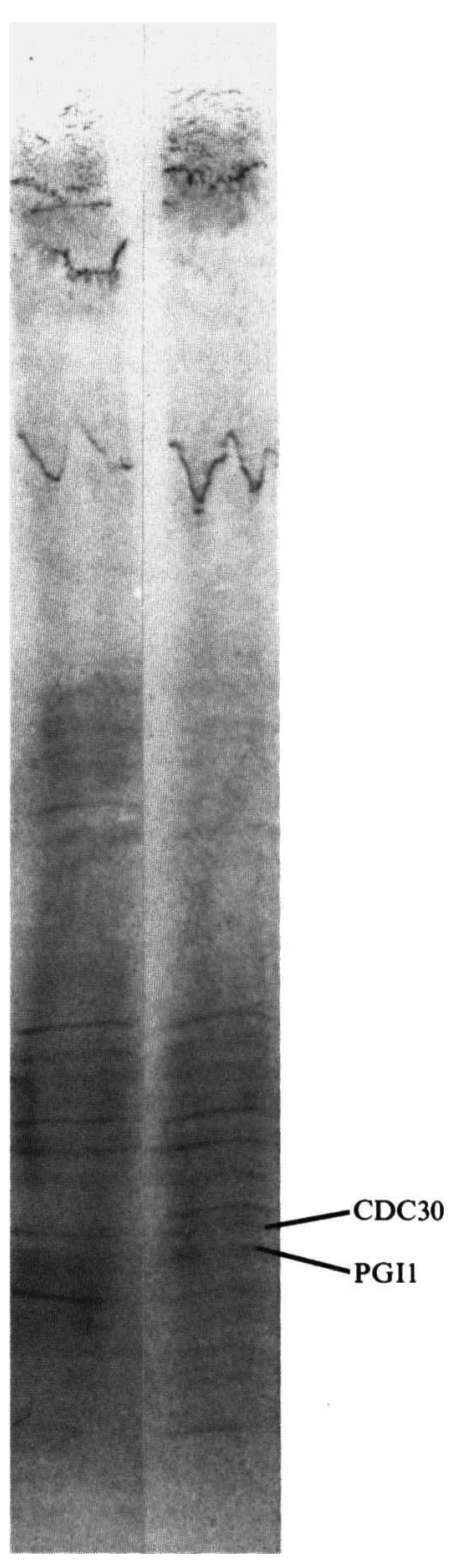

Fig. 1. Isoelectric focusing gel showing the isoenzymes of phosphoglucose isomerase from strain AAG2 (lane 1), which has a deletion in the PGIl gene, and wild-type strain A364A (lane 2). The cells were grown in YEPF medium supplemented with $0.055 \%$ glucose. Similar amounts of protein $(100 \mu \mathrm{g})$ were applied in each case. The individual isoenzymes were identified by comparison with samples of purified enzymes which were co-electrophoresed in separate lanes.

the de novo synthesis of considerable amounts of both of these materials (Cabib et al., 1974; Cabib, 1975). At the permissive temperature $\left(25^{\circ} \mathrm{C}\right)$ the $c d c 30$-bearing mutant 23015 contains approximately $73 \%$ of the polysaccharide present in the wild-type strain A364A (Table 1). This is presumably because even at the permissive temperature phosphoglucose isomerase activity is reduced by a similar proportion in the mutant (Dickinson 
Table 1. The cdc30 mutation results in reduced polysaccharide content

\begin{tabular}{llcc}
\hline \hline & & \multicolumn{2}{c}{$\begin{array}{c}\text { Polysaccharide content } \\
\text { (ng glucose equivalent per cell) }\end{array}$} \\
\cline { 3 - 4 } Strain & $\begin{array}{l}\text { Relevant } \\
\text { genotype }\end{array}$ & $\begin{array}{c}\text { Cultured at } \\
25^{\circ} \mathrm{C}\end{array}$ & $\begin{array}{c}5 \mathrm{~h} \text { after shift-up } \\
\text { to } 36.5{ }^{\circ} \mathrm{C}\end{array}$ \\
\hline A364A & Wild-type & $0.440 \pm 0.140$ & $0.430 \pm 0.005$ \\
23015 & $c d c 30$ & $0.320 \pm 0.008$ & $0.033 \pm 0.003$ \\
\hline \hline & & &
\end{tabular}

\& Williams, 1987). However, after $5 \mathrm{~h}$ at $36.5^{\circ} \mathrm{C}$, when the $c d c 30$-bearing strain has cell cycle arrested, it contains less than $8 \%$ of the polysaccharide of the wildtype. Note that these results express polysaccharide content per cell. There is no destruction of polysaccharide in strain 23015 during the temperature shift-up: the amount of polysaccharide assayed increased compared with zero time, but not as fast as cell density during the same period. This offers a clear biochemical explanation of why a strain carrying a $c d c 30$ mutation should arrest late in nuclear division: the $C D C 30$ gene product is not required for nuclear division, but is needed to provide precursors for mannan and chitin synthesis in the subsequent stages of the cell cycle (cytokinesis and separation). Hence, because a $c d c 30$-bearing mutant cannot execute these processes it appears to arrest late in nuclear division. Staining with the reagent DAPI $(4,6-$ diamidino-2-phenylindole) has revealed that $c d c 30$ arrested cells have completed nuclear division; two separate nuclei can be seen in such cells (D. Cole \& J. R. Dickinson, unpublished result). It might be argued that reduced polysaccharide content could be a non-specific consequence of cell cycle arrest after a temperature shiftup. This seems unlikely for any cell cycle mutant arresting near the $c d c 30$ block point because, as already stated, the cell normally makes more of this material at this stage of the cell cycle.

\section{Isolation of revertants of the pgil-1 mutant}

The initial screening yielded 300 revertants that were capable of growth on YEPD at $25^{\circ} \mathrm{C}$. These were classified into those which were temperature-sensitive for growth on glucose ('DTS' strains for Dextrose Temperature Sensitive, of which there were 35); temperature-sensitive for growth on ethanol ('ETS' strains for Ethanol Temperature Sensitive, of which there were 5) and temperature-sensitive for growth on glycerol ('GTS' strains for Glycerol Temperature Sensitive, of which there were 3). All of the strains that were temperature-sensitive on glucose showed reduced growth rather than zero growth at $36^{\circ} \mathrm{C}$. All of these strains (DTS1-35) were also temperature-sensitive for growth on ethanol in that they showed reduced growth on this substrate at the elevated temperature. In contrast, strains ETS1-5 and GTS1-3 were only temperature sensitive for growth on ethanol and glycerol, respectively.

Temperature shift-up of small cultures in liquid YEPD always involved the simultaneous use of strains A364A, 23015 and JPT99: the former as a wild-type control, the latter two as definitive $c d c 30$-bearing strains. These experiments suggested that strains DTS1, DTS8, DTS12, DTS26 and DTS27 were all potential cell cycle mutants arresting as unbudded cells after a $5 \mathrm{~h}$ shift-up to $36^{\circ} \mathrm{C}$. These strains were then all re-tested in conical flasks filled to $40 \%$ of nominal capacity, after which only DTS 12 could be definitely assigned as a cell cycle mutant. With the other revertants it was not possible to distinguish whether they had very long cell cycle times or whether after $5 \mathrm{~h}$ at $36^{\circ} \mathrm{C}$ they had completely stopped cell cycling. However, after $5 \mathrm{~h}$ at $36^{\circ} \mathrm{C}$ a culture of DTS 12 was $85 \%$ unbudded. Six hours after the temperature shift-up the culture was $92 \%$ unbudded. At this time a portion of the culture was returned to $25^{\circ} \mathrm{C}$. Cell cycling restarted shortly thereafter as evidenced by the proportion of budded cells in the population.

\section{Genetic characterization of the mutation in strain DTS 12}

In order to test whether strain DTS12 arose from an intragenic or extragenic reversion event an outcross was made to spores of the homothallic strain $59.4 \mathrm{~A}$. The resulting diploid was sporulated and the spores cultured on YEPF, which permits the germination and growth of strains carrying the pgil mutation. The main reason for using this $s p d l$-carrying strain was to facilitate sporulation of the diploid resulting from the mating. As with other mutations affecting the glycolytic/gluconeogenic sequence, the pgil mutation causes much reduced sporulation in the heterozygous state and asporogeny in homozygous diploids (Maitra \& Lobo, 1977; Aguilera, 1986), whereas the $s p d l$ mutation can restore sporulation in such cells (Dickinson \& Williams, 1986). If the reversion event in DTS12 had taken place within the $P G I I$ gene this cross would be expected to reveal only the temperature-sensitive pgil allele. On the other hand, even if a new suppressor mutation produced no phenotype when it occurred on its own, its presence in DTS 12 could be deduced by segregation of the original (absolute) pgil-1 mutation in spore progeny of this cross. All of the 390 clones recovered in this random spore analysis either grew normally on glucose or were temperature-sensitive for growth on glucose; there were no spore clones displaying an absolute failure to grow on 
Table 2. Effect of glucose concentration in the medium on growth and proliferation

Strain DTS12 was grown in YEP medium containing different initial concentrations of D-glucose. To ensure adequate aeration the cells were grown in a gyrorotatory shaker at $25^{\circ} \mathrm{C}$ in conical flasks filled to $5 \%$ of the nominal capacity.

\begin{tabular}{cccc}
\hline \hline \multirow{2}{*}{$\begin{array}{c}\text { Initial glucose } \\
\text { conc in medium } \\
(\%, \mathrm{w} / \mathrm{v})\end{array}$} & \multicolumn{3}{c}{ Optical density $(600 \mathrm{~nm})$} \\
\cline { 2 - 4 } & $51 \mathrm{~h}$ & $64 \mathrm{~h}$ & $111 \mathrm{~h}$ \\
\hline 0.5 & 0.749 & 3.29 & 14.13 \\
1.0 & 0.350 & 1.08 & 21.15 \\
2.0 & 0.143 & 0.31 & 10.56 \\
\hline \hline
\end{tabular}

YEPD. This indicates that strain DTS12 arose from an intragenic reversion event in the $P G I I$ gene.

Further information comes from two complementation studies. In the first, DTS12 was mated to strain 23015 on YEPF at $25^{\circ} \mathrm{C}$. The mutation in DTS12 complemented the $c d c 30$ mutation in 23015 because the diploid was capable of growth on YEPD at $36^{\circ} \mathrm{C}$ whereas neither of the parental haploids was. Hence the mutation in DTS12 cannot be in the CDC30 gene. The second experiment of this sort involved mating DTS12 with strain 26.1A (MATa pgil). The resulting diploid was temperature-sensitive on YEPD, which indicates that the temperature-sensitive mutation in DTS12 is an allele of $P G I 1$. It is unlikely that the reversion mutation that took place within the pgil-l allele was in the same codon as the original pgil-1 mutation, hence this double mutation has been called 'pgil-1,100'.

\section{Physiological characterization of the pgil-1,100 mutation}

Strains carrying the pgil-1,100 mutation proliferate better at the permissive temperature in glucose concentrations below the $2 \%$ used in normal YEPD medium. Table 2 shows that up to $64 \mathrm{~h}$ biomass is inversely proportional to the original glucose concentration in the medium. At the end of the experiment the cells in $0.5 \%$ and $1 \%$ glucose had grown more than those in $2 \%$ glucose; although, more in line with one's usual experience, cells supplied with $1 \%$ glucose eventually outgrew those in $0.5 \%$ glucose. These findings are reminiscent of the work of Aguilera, who showed that deletion of the $P G I I$ gene resulted in a failure to grow on glucose concentrations above $0.5 \%$ (Aguilera, 1986) and that in a strain with an extragenic suppressor of the pgild mutation growth was completely inhibited by glucose concentrations greater than $0.4 \%$ (Aguilera, 1987).

The explanation for this is presumably that a cell with a much reduced capacity to convert G6-P into F6-P is very prone to poisoning by the accumulation of G6-P. Accumulation of G6-P will be more acute the higher the

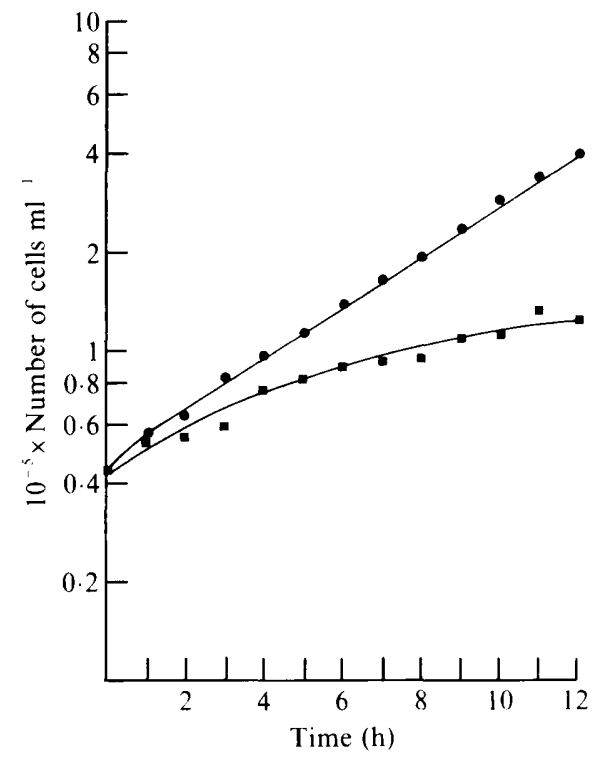

Fig. 2. Effect of a temperature shift-up on strain DTS12. A culture was grown at the permissive temperature of $25^{\circ} \mathrm{C}$ in YEP medium containing $0.5 \%$ glucose and was then divided into two equal portions: one remained at $25^{\circ} \mathrm{C}(0)$; the other was shifted to the restrictive temperature of $36^{\circ} \mathrm{C}(\mathbf{\square})$.

concentration of supplied glucose. Because of this finding all subsequent physiological experiments used an initial glucose concentration of $0.5 \%$.

Cells of DTS12 from the exponential phase in YEP $+0.5 \%$ glucose arrested when shifted from $25^{\circ} \mathrm{C}$ to $36{ }^{\circ} \mathrm{C}$ (Fig. 2). There was no increase in cell number at the restrictive temperature after $11 \mathrm{~h}$. Cells maintained at the permissive temperature did not arrest (Fig. 2). Fig. 3 shows the typical morphology of arrested cells, which were blocked at the unbudded stage of the cell cycle. The majority of arrested cells appeared as pairs (Fig. $3 a-c$ ); however, very gentle sonication revealed that the cells had completed cell separation and were only loosely adherent (Fig. 3d).

Initially, it was surprising to find that the temperaturesensitive pgil-1,100 mutation caused cell cycle arrest in the G1 unbudded portion of the cell cycle. Before the work began the expectation had been that if such a mutation could be isolated it would cause arrest at the same point in the cell cycle as the $c d c 30$ mutation. Isolation of this mutation serves to explain some puzzles concerning the regulation of phosphoglucose isomerase activity during the yeast cell cycle. In a paper to be published elsewhere it will be reported that phosphoglucose isomerase undergoes a stepwise doubling of activity at one of two different points in the cell cycle (depending upon the particular synchronization method used). These correspond to the $c d c 30$ and pgil-1,100 arrest points. The recognition that there are two genes encoding two different isoenzymes of phosphoglucose isomerase would 

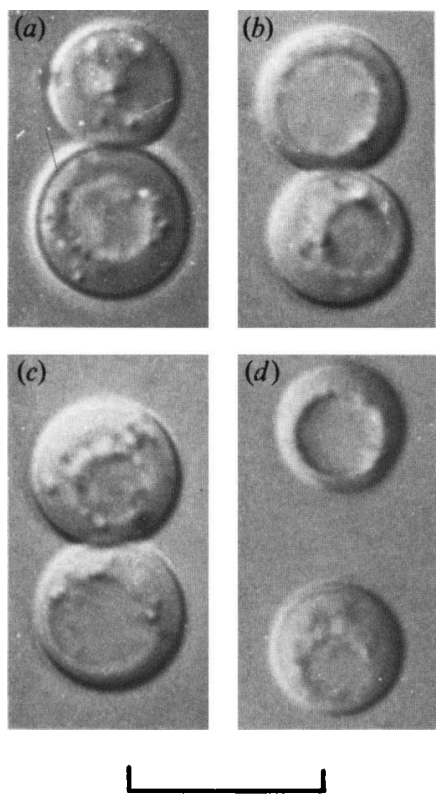
1

$10 \mu \mathrm{m}$

Fig. 3. Terminal phenotype of a pgil-1,100-bearing strain after arrest at the restrictive temperature. Cells were viewed by differential interference contrast optics. Panel $(d)$ shows cells that were gently sonicated immediately prior to photography.

lead one to expect that there might be two different cell cycle mutations. As far as the author is aware, this is the first time that a cell cycle mutation has been isolated in this way. Both the mutant's physiology and the molecular details of the new allele require further characterization, but this does not detract from the conclusions reported here.

I am grateful to M. F. Claridge for the use of isoelectric focusing equipment and I am indebted to Andres Aguilera, Pabitra Maitra and John Pringle for sending me their strains. I thank Tony Williams, Pete Ashley and Debbie Cole for expert technical assistance.

\section{References}

Aguilera, A. (1986). Deletion of the phosphoglucose isomerase structural gene makes growth and sporulation glucose dependent in Saccharomyces cerevisiae. Molecular and General Genetics 204, 310316.

AGUiLera, A. (1987). Mutations suppressing the effects of a deletion of the phosphoglucose isomerase gene PGII in Saccharomyces cerevisiae. Current Genetics 11, 429-434.

Aguilera, A. \& ZimmermanN, F. K. (1986). Isolation and molecular analysis of the phosphoglucose isomerase structural gene of Saccharomyces cerevisiae. Molecular and General Genetics 202, 83-89.
CABIB, E. (1975). Molecular aspects of yeast morphogenesis. Annual Review of Microbiology 29, 191-214.

Cabib, E., Ulane, R. \& Bowers, B. (1974). A molecular model for morphogenesis: the primary septum of yeast. Current Topics in Cellular Regulation 8, 1-32.

Ciriacy, M. \& Breitenbach, I. (1979). Physiological effects of seven different blocks in glycolysis in Saccharomyces cerevisiae. Journal of Bacteriology 139, 152-160.

Clifton, D., Weinstock, S. B. \& Fraenkel, D. (1978). Glycolysis mutants in Saccharomyces cerevisiae. Genetics 88, 1-11.

DiCKInson, J. R. \& DaWES, I. W. (1983). Ammonium ion repression of sporulation in Saccharomyces cerevisiae. Journal of General Microbiology 129, 1883-1888.

Dickinson, J. R. \& Williams, A. S. (1986). A genetic and biochemical analysis of the role of gluconeogenesis in sporulation of Saccharomyces cerevisiae. Journal of General Microbiology 132, 2605-2610.

Dickinson, J. R. \& Williams, A. S. (1987). The $c d c 30$ mutation in Saccharomyces cerevisiae results in a temperature-sensitive isoenzyme of phosphoglucose isomerase. Journal of General Microbiology 133, 135-140.

Dickinson, J. R., Smith, M. E., Swanson, T. R., Williams, A. S. \& WINGFIELD, J. M. (1988). The $c d c 30$ mutation in Saccharomyces cerevisiae affects phosphoglucose isomerase, the cell cycle and sporulation. Journal of General Microbiology 134, 2475-2480.

Dubois, M., Gilles, K. A., Hamilton, J. K., Rebers, P. A. \& Smith, F. (1956). Colorimetric method for determination of sugars and related substances. Analytical Chemistry 28, 350-356.

Green, J. B. A., Wright, A. P. H., Cheung, W. Y., Lancashire, W. E. \& HARTLEY, B. S. (1988). The structure and regulation of phosphoglucose isomerase in Saccharomyces cerevisiae. Molecular and General Genetics 215, 100-106.

Herrera, L. S. \& PASCUal, C. (1978). Genetical and biochemical studies of glucosephosphate isomerase mutants in Saccharomyces cerevisiae. Journal of General Microbiology 108, 305-310.

Kaback, D. B., Oeller, P. W., Steensma, H. Y., Hirschman, J., Ruezinsky, D., Coleman, K. G. \& Pringle, J. R. (1984). Temperature-sensitive lethal mutations on yeast chromosome I appear to define only a small number of genes. Genetics 108, 67-90.

KAWASAKI, G. H. (1979). Karyotypic instability and carbon source effects in cell cycle mutants of Saccharomyces cerevisiae. $\mathrm{PhD}$ thesis, University of Washington, Seattle, USA.

Kempe, T. D., Nakagawa, Y. \& Noltmann, E. A. (1974a). Physical and chemical properties of yeast phosphoglucose isomerase isoenzymes. Journal of Biological Chemistry 249, 4617-4624.

Kempe, T. D., Gee, D. M., Hathaway, G. M. \& Noltmann, E. A. $(1974 b)$. Subunit and peptide compositions of yeast phosphoglucose isomerase isoenzymes. Journal of Biological Chemistry 249, 46254633.

MaITRA, P. K. (1971). Glucose and fructose metabolism in a phosphoglucoseisomeraseless mutant of Saccharomyces cerevisiae. Journal of Bacteriology 107, 759-769.

MaITRA, P. K. \& LoBo, Z. (1977). Genetic studies with a phosphoglucose isomerase mutant of Saccharomyces cerevisiae. Molecular and General Genetics 156, 55-60.

MORTIMER, R. K. \& HaWthorne, D. C. (1975). Genetic mapping in yeast. Methods in Cell Biology 11, 221-233.

NakaGawa, Y. \& NoltmanN, E. A. (1967). Multiple forms of yeast phosphoglucose isomerase. I. Resolution of the crystalline enzyme into three isoenzymes. Journal of Biological Chemistry 242, 47824788.

Pringle, J. R. (1987). The gene number paradox and the complexity of the cell-division cycle and other cellular processes. In Modern Cell Biology, vol. 5, pp. 299-306. Edited by C. Waymouth. New York: Alan R. Liss.

ShERMAN, F. (1975). Use of micromanipulators in yeast studies. Methods in Cell Biology 11, 189-199. 